\title{
Long-term follow-up of patients with malignant pedunculated colon polyps after colonoscopic polypectomy
}

\author{
Hugh James Freeman MD CM FRCPC FACP
}

HJ Freeman. Long-term follow-up of patients with malignant pedunculated colon polyps after colonoscopic polypectomy. Can J Gastroenterol 2013;27(1):20-24.

BACKGROUND: Previously published studies have suggested that patients with resected colon cancer have an increased risk for early metachronous colon cancer. Current screening guidelines recommend intense surveillance by colonoscopy for the initial five years after the initial colon cancer has been resected. Information regarding endoscopically removed malignant polyps is limited.

METHODS: In the present study, 25 consecutive patients (14 male, 11 female) with malignant pedunculated colon polyps treated with snare cautery polypectomy were followed for more than one decade up to 20 years. Five patients required an additional resection to ensure that removal of the original cancer was complete. Annual colonoscopies were planned for five years. If an adenoma was detected in the fifth year, colonoscopy was performed annually until no adenomas were detected. Otherwise, colonoscopy was planned every three years after five years.

RESULTS: In the present study, there was no mortality from colon cancer and no patient developed either recurrent colon cancer or an early metachronous colon cancer during the initial five-year period of surveillance. Two patients (one male, one female) ultimately developed late cecal cancers almost one decade after the original colon cancers were resected. One had an early stage cancer that was resected, while the other had an infiltrating mucinous carcinoma complicating a small tubulovillous adenoma with extension to a single lymph node. After surgical removal and adjuvant chemotherapy, no further neoplastic disease has been detected.

CONCLUSIONS: Overall, patients with malignant pedunculated polyps do extremely well if appropriately managed at the time of the initial polypectomy. Short-term outcomes after removal of a malignant polyp(s) appear to be similar to those with a nonmalignant polyp. However, late metachronous colon cancer may still occur. Long-term follow-up should be considered in each patient, assuming reasonable life expectancy, because risk of additional adenomas and metachronous colon cancer persists even after the initial five years of currently recommended surveillance. Patients with resected malignant polyps may represent a special patient subgroup that requires surveillance for more extended periods than current guidelines have recommended.

Key Words: Adenoma; Colon cancer; Colonic adenocarcinoma; Colonoscopic polypectomy, Malignant colon polyps; Metachronous colon cancer

Colorectal cancer is a common malignancy in men and women. If there is no lymph node involvement, the reported survival rate after surgical resection of early stage colorectal cancer is more than $80 \%$ at five years. In the past three decades, colonoscopic removal of malignant polyps has been accomplished; however, long-term, systematically collected follow-up data in this important subgroup are very limited and needed.

In a recent pooled analysis of eight prospective studies with a mean follow-up period of less than four years that included 9167 men and
Le suivi à long terme des patients ayant des polypes pédonculés malins du côlon après une polypectomie coloscopique

HISTORIQUE : Des études déjà publiées laissent supposer que les patients ayant un cancer du côlon réséqué présentent un risque plus élevé de cancer métachrone précoce du côlon. Les lignes directrices actuelles sur le dépistage recommandent une surveillance intense par coloscopie pendant les cinq années suivant la résection du premier cancer du côlon. L'information relative à la résection des polypes malins est limitée.

MÉTHODOLOGIE : Dans la présente étude, 25 patients consécutifs (14 hommes, 11 femmes) ayant des polypes pédonculés malins du côlon traités par polypectomie par cautère en anse ont été suivis pendant plus de dix ans et jusqu'à 20 ans. Cinq patients ont eu besoin d'une résection supplémentaire afin de s'assurer de la résection complète du premier cancer. Des coloscopies annuelles ont été planifiées pendant cinq ans. Si on décelait un adénome la cinquième année, la coloscopie était effectuée tous les ans jusqu'à ce qu'on ne décèle plus d'adénome. Autrement, au bout de cinq ans, la coloscopie était planifiée tous les trois ans.

RÉSULTATS : Dans la présente étude, les chercheurs n'ont pas observé de mortalité causée par le cancer du côlon, et aucun patient n'a présenté de récurrence du cancer du côlon ou un cancer métachrone précoce du côlon pendant la première période de surveillance de cinq ans. Deux patients (un homme, une femme) ont fini par présenter des cancers cæcaux tardifs près de dix ans après la résection du cancer du côlon original. L'un avait un cancer en phase précoce qui a été réséqué, tandis que l'autre présentait un carcinome mucineux infiltrant compliquant un petit adénome tubulovilleux métastasé dans un seul ganglion lymphatique. Après la résection chirurgicale et la chimiothérapie adjuvante, aucune maladie néoplasique supplémentaire n'a été décelée.

CONCLUSIONS : Dans l'ensemble, les patients ayant des polypes pédonculés malins s'en tirent très bien s'ils sont bien pris en charge dès la polypectomie initiale. Les issues à court terme après la résection de polype(s) malin(s) semblent similaires à celles des personnes ayant des polypes non malins. Cependant, un cancer métachrone tardif du côlon demeure une possibilité. Le suivi à long terme devrait être envisagé chez chaque patient, sous réserve d'une espérance de vie raisonnable, parce que le risque d'adénomes supplémentaires et de cancer métachrone du côlon persiste même après les cinq premières années recommandées pour la surveillance. Les patients ayant subi l'ablation des polypes malins peuvent constituer un sous-groupe spécial de patients qui ont besoin d'une surveillance plus longue que ce que les lignes directrices actuelles recommandent.

women with previously resected benign adenomas (1), advanced neoplasia developed in $11.8 \%$, including 58 patients with invasive carcinoma. However, information on follow-up after removal of malignant polyps was limited, especially for extended periods of surveillance.

In the National Polyp Study (2), evidence for long-term prevention of colon cancer following colonoscopic polypectomy was recently collected and compared with controls. Information collected from death certificates showed that at least 12 patients experienced death attributed to a colon cancer six or more years after the baseline

Department of Medicine (Gastroenterology), University of British Columbia, Vancouver, British Columbia

Correspondence: Dr Hugh James Freeman, Department of Medicine (Gastroenterology), University of British Columbia Hospital, 2211 Wesbrook Mall,

Vancouver, British Columbia V6T 1W5. Telephone 604-822-7216, fax 604-822-7236, e-mail hugfree@shaw.ca

Received for publication March 16, 2012. Accepted June 24, 2012 
colonscopy, and five cases of colorectal cancer were detected during surveillance (2). More long-term information focused on patients with endoscopically removed malignant polyps would be valuable.

Guidelines published by the American Cancer Society and the United States Multi-Society Task Force have recommended surveillance colonoscopies for asymptomatic persons following early stage colon cancer (after clearing of synchronous neoplasia) at least one, three and five years after resection and, if adenomas are detected, shorter intervals during these five years may be indicated (3). Colonoscopy in the perioperative period for 'clearing', and again within one year of resection, has also been recommended because early interval cancers have been reported in older studies (4-7), in part, to reduce the risk for early interval metachronous colon cancer (8). However, guidelines after this initial five-year period of intense follow-up based on systematic evaluation of patients with initially resected malignant polyps are very limited and more information from longterm studies is needed.

\section{METHODS}

All patients with 'sporadic' malignant pedunculated colon polyps evaluated and treated with endoscopic polypectomy by the investigator during a 15-year period from 1990 to 2005 were prospectively evaluated, with surveillance colonoscopy planned annually for a minimum duration of five years and then at least every three years progressing up to and including 2011. A 'clearing' colonoscopy, including the cecum and ileal orifice, was performed at the time of the initial procedure, or within three to six months after the malignant polyp was endoscopically resected. Patients with a personal or family history of intestinal neoplasia, including previously resected adenomas, or underlying inflammatory bowel disease were excluded from the present evaluation.

Before entering the surveillance program, standard laboratory tests were performed including a hemogram, liver chemistry tests and measurement of carcinoembryonic antigen (CEA) levels. In addition, radiological imaging studies were performed, which included computed tomography (CT) scanning.

In all patients, colon cancer was established by a pathologist with expertise in the diagnosis and pathological staging of colon cancer using a standardized classification $(9,10)$. All polyps were endoscopically assessed as macroscopically pedunculated with a visible stalk, resected by snare loop cautery, and usually marked at the time of resection with inkspot using $1 \mathrm{~mL}$ to $2 \mathrm{~mL}$ submucosal injections $1 \mathrm{~cm}$ to $2 \mathrm{~cm}$ distal to the polyp site. Polyps were described on the basis of size, type (ie, villous features) and, if malignancy was detected, degree of differentiation. Patients were included in the present analysis only if malignancy had invaded through the muscularis mucosa into the polyp stalk or submucosa (T1, Duke's A, Stage 1), but not included if there was extension into the muscularis propria. Patients with polyps labelled as intramucosal carcinoma were excluded (ie, Tis).

For each polyp, a microscopic estimate of distance from the cautery line was also provided. If invasive cancer was defined inside $2 \mathrm{~mm}$ of the cautery line, or if the invasive cancer appeared to actually cross the cautery line or if definition was not possible, then surgical referral for a segmental resection was performed. In these patients, the resected colon specimen and lymph nodes were examined to exclude invasion into the muscularis propria or lymph node involvement.

\section{Surveillance studies}

After entry into the study, patients were scheduled for annual colonoscopy for five years with removal of any visualized polyps and, if colonoscopy failed to reveal any neoplastic disease at the five-year colonoscopy, additional colonoscopies were scheduled every three years in a second, but less-intense phase of surveillance. If neoplastic disease was detected at five years, annual colonoscopic evaluation was continued until no neoplastic disease was detected, then colonoscopies were subsequently scheduled every three years. Cessation of each individual surveillance program following completion of the initial five years of intensive surveillance was arbitrary but based on clinical assessment related to age and the presence of concomitant comorbidities. Although other medical problems in this aging population developed (eg, cardiopulmonary, cerebrovascular or neurodegenerative disease), none prohibited bowel cleansing or colonoscopy. Before the procedures, anticoagulants or acetylsalicylic acid were discontinued for four days; however, other medications were permitted.

\section{Procedures}

Visualized polyps were removed after a standard bowel preparation, and routine written consent for colonoscopy and polypectomy was obtained before each procedure. This approval also required that specific permission be obtained to use collected medical data information for quality assurance review and medical reporting. Most patients were administered a combination of intravenous sedative and narcotic before the procedure; some requested that the procedure be performed with narcotic alone or without medication. Over the 15-year period of the study, both standard and high-definition colonoscopes were used. At each colonoscopy, the size and location of each polyp was defined and pathological evaluation was performed on all resected polyps to confirm the presence of neoplastic change (adenoma, tubulovillous adenoma, villous adenoma). Biopsies were also routinely performed at previous surgical anastomoses in the colon to further exclude microscopic evidence of recurrent cancer.

\section{Cancers and advanced adenomas}

Synchronous colon cancer was defined before initiation of the study as a second colon cancer detected at the time of the initial colon cancer diagnosis or within three to six months, if another colonoscopy was required to ensure clearing of the colon. Metachronous colon cancer was defined before initiation of the study as any subsequent colon cancer detected during anytime in the follow-up surveillance period. Adenomas detected during any colonoscopic evaluation were also completely removed and each polyp was independently recorded to include estimated size and location. Advanced adenomas were defined based on one or more of the following criteria as noted elsewhere (11): estimated size $>1 \mathrm{~cm}$; pathological detection of villous components in the adenoma; or high-grade dysplasia.

\section{Patient demographics}

\section{RESULTS}

There were 25 patients, each with a single malignant pedunculated colon polyp removed by colonoscopic snare cautery polypectomy. The patient sample (overall mean age 58.2 years) included 14 males (56\%; mean age 59.2 years; range 42 to 77 years) and 11 females (44\%; mean age 56.8 years; range 33 to 79 years) (Table 1 ). No patient had a synchronous malignant lesion.

All patients were symptomatic for less than one year before the colonoscopic procedure. As shown in Table 1, males or females usually had evidence of blood loss before referral, including occult bloodpositive stools or grossly visible rectal bleeding or mild anemia (all had hemoglobin measurements $>110 \mathrm{~g} / \mathrm{L}$ ). Some also noted vague or poorly localized abdominal pain or discomfort, as well as a change in usual bowel habit including constipation, diarrhea or altered frequency with normal stools. Apart from mild anemia, sometimes with iron deficiency, liver chemistry tests and CEA levels were reported within the normal range, while CT imaging showed no evidence of metastases.

\section{Malignant polyps}

All malignant polyps were located in the sigmoid or descending colon. At colonoscopy, polyp size was estimated to be $1 \mathrm{~cm}$ to $4 \mathrm{~cm}$, and each was reported to show an underlying tubular $(n=11$ [42.3\%]) or tubulovillous ( $\mathrm{n}=15$ [57.7\%]) adenoma with the complicating adenocarcinoma invading through the muscularis mucosa. No polypoid carcinomas were seen. Each carcinoma was reported as either well differentiated (18 of 26 [69.2\%]) or moderately differentiated (eight of 26 [30.8\%]). 
TABLE 1

Patients with malignant colon polyps $(n=25)$

\begin{tabular}{|c|c|c|c|c|c|}
\hline Patient age, years/sex & Symptoms & $\begin{array}{l}\text { Anatomical } \\
\text { location }\end{array}$ & $\begin{array}{c}\text { Year } \\
\text { diagnosed }\end{array}$ & $\begin{array}{c}\text { Follow-up, } \\
\text { years }\end{array}$ & Year last seen \\
\hline 44/female & Bleeding & Sigmoid colon & 1998 & 9 & 2009 \\
\hline $55 /$ male & Altered bowel habit & Sigmoid colon & 2003 & 8 & 2011 \\
\hline 56/female & Abdominal pain & Sigmoid colon & 2005 & 5 & $2010^{*}$ \\
\hline $59 /$ male & Bleeding & Sigmoid colon & 1998 & 5 & $2003^{\dagger}$ \\
\hline 55/female & Bleeding & Sigmoid colon & 1998 & 10 & 2008 \\
\hline $71 /$ male & Bleeding & Sigmoid colon & 1995 & 15 & 2010 \\
\hline $60 /$ male & Bleeding & Sigmoid colon & 1993 & 17 & 2010 \\
\hline 79/female & Bleeding & Sigmoid colon & 2005 & 5 & $2010^{*}$ \\
\hline $65 /$ male & Bleeding & Descending colon & 2004 & 7 & 2011 \\
\hline 59/female & Bleeding and altered bowel habit & Sigmoid colon & 1995 & 15 & 2010 \\
\hline 47/male & Abdominal pain & Sigmoid colon & 1997 & 13 & 2010 \\
\hline 73/female & Bleeding & Sigmoid colon & 1993 & 17 & $2010^{\ddagger}$ \\
\hline 42/male & Altered bowel habit & Sigmoid colon & 2002 & 9 & 2011 \\
\hline $61 /$ female & Abdominal pain & Descending colon & 2000 & 8 & 2008 \\
\hline 58/male & Bleeding & Sigmoid colon & 2000 & 8 & 2008 \\
\hline $77 /$ male & Bleeding & Sigmoid colon & 2005 & 5 & 2010 \\
\hline 68/male & Bleeding & Sigmoid colon & 1995 & 13 & 2010 \\
\hline $61 /$ female & Abdominal pain and bleeding & Sigmoid colon & 1997 & 15 & 2011 \\
\hline 33/female & Bleeding & Sigmoid colon & 1999 & 11 & $2010^{*}$ \\
\hline 46/male & Bleeding & Sigmoid colon & 2001 & 9 & 2010 \\
\hline 52/male & Bleeding & Sigmoid colon & 2001 & 9 & 2010 \\
\hline $68 /$ male & Bleeding & Sigmoid colon & 2000 & 10 & 2010 \\
\hline 53/female & Bleeding & Sigmoid colon & 1996 & 13 & 2009 \\
\hline $61 /$ male & Abdominal pain & Sigmoid colon & 1991 & 19 & 2010 \\
\hline 51/female & Bleeding & Sigmoid colon & 1998 & 12 & $2010^{*}$ \\
\hline
\end{tabular}

${ }^{*}$ Polypectomy followed by negative resection; ${ }^{\dagger}$ Lost to follow-up (moved to Arizona, USA); ${ }^{\ddagger}$ Polypectomy followed by positive resection (T1, see text)

A total of five patients were referred for colon resection within three to four weeks of the initial colonoscopic polypectomy. In all, the indication was to ensure that all invasive neoplasia were removed because pathological evaluation indicated that invasive carcinoma was estimated to be $<2 \mathrm{~mm}$ from the cautery line. In one of the five resected colon specimens, a single focus of neoplastic cells was localized in the submucosa at the polypectomy site but cancer was not invading the muscularis propria or lymph nodes. In the other four cases, no invasive neoplasm was detected at the polypectomy site or in the resected specimen, including the lymph nodes. Subsequent biopsies of the anastomoses revealed no neoplasia.

\section{Follow-up evaluations}

Table 2 summarizes the follow-up studies. With the exception of four patients, all underwent five annual follow-up colonoscopies during the initial five years. Of these four patients, two women completed five years of follow-up with four procedures, but these included a colonoscopy at five years. One man underwent six colonoscopies over eight years, including a colonoscopy at five years. The other man (77 years of age) underwent only three colonoscopies and developed a metastatic neuroendocrine carcinoma of the bladder. He died at 82 years of age, approximately two years after his last colonoscopy. In total, 24 of 26 (92\%) patients, continued surveillance up to 2008 to 2011 . One male patient moved to Arizona (USA) after his fifth colonoscopy and represented the single patient in the present series lost to follow-up from 2003. Overall, the mean duration of colonoscopic follow-up for all 25 patients was more than one decade ( 10.7 years: males 10.5 years; females 10.9 years) with a range of five to 19 years (males five to 19 years; females five to 17 years).

\section{Follow-up procedures}

There were a total of 184 colonoscopies performed by the investigator in the present cohort (including 101 procedures in 15 males, corresponding to a mean of 7.2 procedures per male, and 83 in 11 females corresponding to a mean of 7.5 procedures per female). During the first five years after removal of the malignant polyp, 124 procedures were performed, followed by an additional 60 in 21 patients during the entire follow-up period up to 20 years. Although other medical problems in this aging population have developed, none prohibited bowel cleansing or performance of colonoscopy. No patient experienced a drug- or procedure-related complication, particularly bleeding or perforation.

\section{Further resective surgery}

During the course of these studies, two patients required an additional colon resection. Both patients (one male and one female, 61 years of age at the initial malignant polyp resection) were symptom free and, after the initial five-year phase of surveillance, were discovered to have sessile cecal polypoid lesions not believed to be amenable to safe endoscopic resection. Both had right hemicolectomies and invasive carcinomas were present in the resected specimens. In one, the carcinoma was defined preoperatively with biopsies, but was localized and had not invaded the muscularis propria or lymph nodes (ie, T1). Subsequent follow-up studies, including colonoscopies, have been normal. In the other, multiple biopsies showed a villous adenoma without carcinoma, but in the resected specimen, a focus of mucinous carcinoma was detected that had invaded the muscularis propria into the serosa (T3) and one of 12 resected lymph nodes were involved. She was treated with adjuvant chemotherapy and subsequent blood studies, including CEA testing and CT imaging scans, have been normal with no evidence of cancer. Additional annual colonoscopies after the second cancer was resected revealed no new abnormalities. Subsequent review of these two cases did not reveal evidence of a preexisting serrated adenoma.

Adenomas and complex adenomas

Collectively, 56 adenomas were present in 15 patients $(60 \%)$. Of these, only six in three different patients $(10.7 \%)$ could be categorized as advanced adenomas with one or more of the following: villous 
features, size $>1 \mathrm{~cm}$ or severe dysplasia. One male patient had two pedunculated adenomatous polyps removed during the third and sixth years of follow-up, respectively. Both polyps were estimated to be $>1 \mathrm{~cm}$ in size each and one of these two polyps also had villous components. One female patient had three adenomatous polyps between $1 \mathrm{~cm}$ and $3 \mathrm{~cm}$ in size (one also with villous features) that were resected during the initial five years of follow-up; this was the same patient who developed a metastatic cecal carcinoma (see above) during the eighth year of follow-up surveillance. Another male had several small tubular adenomas resected from the sigmoid colon along with an adenomatous polyp from the ascending colon showing severe focal dysplasia during the sixth year of follow-up; this was the same patient who later also developed a cecal carcinoma in the ninth year of follow-up. In both of these patients, good bowel preparations were recorded as was normal cecal visualization.

\section{DISCUSSION}

In the present long-term prospective evaluation, advanced colonic neoplasia, including invasive metachronous cancers, remained an ongoing risk and developed following endoscopic removal of the initial malignant colon polyp. In contrast to previous short-term studies following colon cancer resection (4-7), early metachronous carcinomas or cancer recurrence were not observed in the present population cohort. Instead, the greatest period of risk for metachronous interval cancer was not during the first year or so after cancer removal (3), but later, only years after the first five years of intense surveillance. As previously suggested (8), the finding of early onset metachronous cancers was likely reflective of missed lesions in these previous studies. However, the risk for later carcinoma persists and does not appear to diminish with time. In both patients who ultimately developed metachronous carcinomas, they were detected almost a decade after the original cancer was removed. This suggests that ongoing surveillance is warranted in medically fit individuals, even beyond five years after cancer resection as defined by current guidelines (2). Additional studies to determine whether there are specific patients who might benefit from extended surveillance are needed. In the present study, patients who eventually developed an invasive carcinoma or required an additional surgical resection had previous advanced adenomas that were endoscopically removed, even though they were not invasive cancers. These patients could represent a biological or genetic subset in a heterogeneous, high-risk population more prone to subsequent development of invasive carcinoma. Additional predictive molecular markers are needed to select individuals who would benefit most from ongoing intensive colonoscopic surveillance following complete removal of malignant polyps.

The number of patients evaluated and followed by a single clinician investigator in a prospective program of surveillance was limited, but shows an almost identical rate of risk for development of advanced colonic neoplasia (ie, 10.7\%) compared with a recently published and larger pooled population of 9167 patients from eight separate prospective surveillance studies followed after removal of an initial benign adenoma rather than a malignant polyp (11.8\%). Although similar, it would be inaccurate to suggest that these are predictive of a comparable prognosis because duration of follow-up in the present cohort was more than 10 years compared with a median of less than four years in the pooled population studies (1). Longer - rather than shorter - duration surveillance studies of larger cohorts with endoscopically resected benign adenomas are needed.

It is generally believed that the most critical element in assessing removal of a malignant pedunculated polyp is the reported distance of the cancer from the stalk cautery resection line. In the five patients who required additional localized colonic resection, only one had a focus of carcinoma in the submucosa that had not invaded the muscularis propria or involved lymph nodes. The other four had no evidence of localized cancer in the resected colon or lymph nodes. As has previously been suggested by others (9), this may reflect localized electrocautery destruction of any residual cancer cells in the region of the
TABLE 2

Follow-up data after malignant polyp resection $(n=25)$

\begin{tabular}{|c|c|c|c|c|c|}
\hline \multirow{3}{*}{$\begin{array}{l}\text { Patient age, } \\
\text { years/sex }\end{array}$} & \multicolumn{2}{|c|}{ Follow-up } & \multicolumn{2}{|c|}{ Polyps } & \multirow{3}{*}{$\begin{array}{c}\text { Metachronous } \\
\text { CRC }\end{array}$} \\
\hline & & Colon & & & \\
\hline & Years & procedures & Total & Advanced & \\
\hline 44/female & 9 & 7 & 0 & 0 & 0 \\
\hline $55 /$ male & 8 & 7 & 0 & 0 & 0 \\
\hline 56/female & 6 & 5 & 0 & 0 & 0 \\
\hline 59/male & 5 & 5 & 1 & 0 & 0 \\
\hline 55/female & 10 & 7 & 1 & 0 & 0 \\
\hline $71 /$ male & 15 & 10 & 0 & 0 & 0 \\
\hline $60 /$ male & 17 & 9 & 2 & 0 & 0 \\
\hline 79/female & 5 & 4 & 1 & 0 & 0 \\
\hline $65 /$ male & 7 & 7 & 12 & 2 & 0 \\
\hline 59/female & 15 & 10 & 0 & 0 & 0 \\
\hline $47 / \mathrm{male}$ & 13 & 5 & 2 & 0 & 0 \\
\hline 73/female & 17 & 7 & 3 & 0 & 0 \\
\hline $42 / \mathrm{male}$ & 9 & 8 & 0 & 0 & 0 \\
\hline 61/female & 8 & 6 & 0 & 0 & 0 \\
\hline 58/male & 8 & 6 & 3 & 0 & 0 \\
\hline $77 /$ male & 5 & 4 & 2 & 0 & 0 \\
\hline $68 /$ male & 13 & 9 & 1 & 0 & 0 \\
\hline 61/female & 15 & 14 & 8 & 3 & $1^{*}$ \\
\hline 33/female & 11 & 7 & 0 & 0 & 0 \\
\hline $46 /$ male & 9 & 6 & 0 & 0 & 0 \\
\hline $52 /$ male & 9 & 8 & 4 & 0 & 0 \\
\hline $68 / \mathrm{male}$ & 10 & 7 & 5 & 0 & 0 \\
\hline 53/female & 13 & 8 & 2 & 0 & 0 \\
\hline 61/male & 19 & 10 & 9 & 1 & $1^{\dagger}$ \\
\hline 56/female & 12 & 8 & 0 & 0 & 0 \\
\hline
\end{tabular}

Data presented as $n .{ }^{*}$ Asymptomatic cecal cancer, mucinous type extending to single lymph node, eighth year of follow-up; ${ }^{\dagger}$ Asymptomatic cecal cancer, early stage T1, no nodes, ninth year of follow-up. CRC Colorectal cancer

cautery site. In a report of eight similar patients (12), all were alive without evidence of disease at five years. The present report extends these observations in five patients to a prolonged period of follow-up: one who required a colon resection remains well with no evidence of disease after five years and, the other four, including the patient with a focus of residual cancer in the resected colon, are all well, each after more than one decade with no evidence of malignant disease.

In the present study, the malignant polyps were pedunculated, only locally invasive, completely resected, and histologically were moderately or well differentiated. In addition, evidence of spread was not evident from imaging studies, subsequent required resective surgery, or based on long-term clinical follow-up and assessment. Clearly, these represent a select group of malignancies with a very positive prognosis from the outset, similar to the experience in other centres focused on histological risk factors $(13,14)$. Except for a single elderly patient who developed an independent and unusual bladder malignancy in the first five years, survival in this surveillance group related to the initial colon cancer was $100 \%$. This contrasts with a frequently cited study (15) that included colorectal cancer patients operated on with curative intent. Despite intensive follow-up with endoscopic and radiological imaging, overall five-year survival rates were not drastically improved. These outcomes more likely reflected the extent of malignancy in their population and, possibly, in retrospect, older technologies. In the present study, two other patients ultimately developed late cecal cancers, one being advanced with extension of a mucinous adenocarcinoma into a single lymph node, suggesting that long-term surveillance for metachronous neoplasms may have limitations in high-risk patients with malignant polyps. While this could represent a 'missed lesion', consistent with the view that colonoscopy may have a 
less 'protective effect' for right-sided lesions, a cancer that is inherently more biologically aggressive (ie, mucinous carcinoma, neuroendocrine carcinoma, poorly differentiated carcinomas) could also be a responsible factor $(2,15,16)$. Finally, although not defined here, a cancer arising from the hypothesized 'alternative' serrated adenoma pathway may be another consideration (17). Additional and much larger studies, preferrably from multiple centres, will be needed to determine

\section{REFERENCES}

1. Martinez ME, Baron JA, Lieberman DA, et al. A pooled analysis of advanced colorectal neoplasia diagnoses after colonoscopic polypectomy. Gastroenterology 2009;136:832-41.

2. Zauber AG, Winawer SJ, O'Brien MJ, et al. Colonoscopic polypectomy and long-term prevention of colorectal-cancer deaths. N Engl J Med 2012;366:687-96.

3. Rex DK, Kahi CJ, Levin B, et al. Guidelines for colonoscopy surveillance after cancer resection: A consensus update by the American Cancer Society and the US Multi-Society Task Force on Colorectal Cancer. Gastroenterology 2006;130:1865-71.

4. Jeffrey M, Hickey BE, Hider PN. Follow-up strategies for patients treated for non-metastatic colorectal cancer. Cochrane Database Syst Rev 2007;(1):CD002200.

5. Bohm B, Schwenk W, Hucke HP, Stock W. Does methodic longterm follow-up affect survival after curative resection of colorectal carcinoma? Dis Colon Rectum 1993:36:280-6.

6. Ovaska JT, Jarvinen HJ, Mecklin JP. The value of a follow-up programme after radical surgery for colorectal carcinoma. Scand J Gastroenterol 1989;24:416-22.

7. Green RJ, Metlay JP, Propert K, et al. Surveillance for second primary colorectal cancer after adjuvant chemotherapy: An analysis of Intergroup 0089. Ann Intern Med 2002;136:261-9.

8. Rulyak SJ, Lieberman DA, Wagner EH, Mandelson MT. Outcome of follow-up colon examination among a population-based cohort of colorectal cancer patients. Clin Gastroenterol Hepatol 2007;5:470-6.

9. Haggitt RC, Glotzbach RE, Soffer EE, Wruble LD. Prognostic factors in colorectal carcinomas arising in adenomas: Implications for lesions removed by endoscopic polypectomy. Gastroenterology 1985;89:328-36. whether more intensive long-term endoscopic imaging studies can improve survival in this selected polyp population. In the present experience, no patient with a malignant polyp died due to a late metachronous colon cancer, including the two patients with cecal carcinomas. Indeed, in both patients, active surveillance and the resultant detection of second completely asymptomatic cancers likely improved their individual survival.

10. Bresalier RS. Malignant neoplasms of the large intestine. In: Feldman M, Friedman LS, Sleisenger MH, eds. Sleisenger and Fordtran's Gastrointestinal and Liver Disease: Pathophysiology, Diagnosis, Management, 7th edn. Philadelphia: WB Saunders Co 2002:2215-61 .

11. Morson BC, Whiteway JE, Jones EA, Macrae FA, Williams CB. Histopathology and prognosis of malignant colorectal polyps treated by endoscopic polypectomy. Gut 1984;25:437-44.

12. Cunningham KN, Mills LR, Schuman BM, Mwakyusa DH. Long-term prognosis of well-differentiated adenocarcinoma in endoscopically removed colorectal adenomas. Dig Dis Sci 1994:39:2034-7.

13. Volk EE, Goldblum JR, Petras RE, Carey WD, Fazio VW. Management and outcome of patients with invasive carcinoma arising in colorectal polyps. Gastroenterology 1995;109:1801-7.

14. Hassan C, Zullo A, Risio M, Rossini FP, Morini S. Histological risk factors and clinical outcome in colorectal malignant polyp: A pooled-data analysis. Dis Colon Rectum 2005;48:1588-96.

15. Schoemaker D, Black R, Giles L, Toouli J. Yearly colonoscopy, liver $\mathrm{CT}$, and chest radiography do not influence 5-year survival of colorectal cancer patients. Gastroenterology 1998;114:7-14.

16. Freeman HJ, Kwan PW, Webber D. Large cell neuroendocrine cancer of the colon following rituximab-based lymphoma treatment. Can J Gastroenterol 2012;26:12-13.

17. Freeman HJ. Heterogeneity of colorectal adenomas, the serrated adenoma, and implications for screening and surveillance. World J Gastroenterol 2008;14:3461-3. 


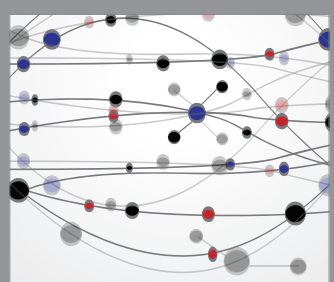

The Scientific World Journal
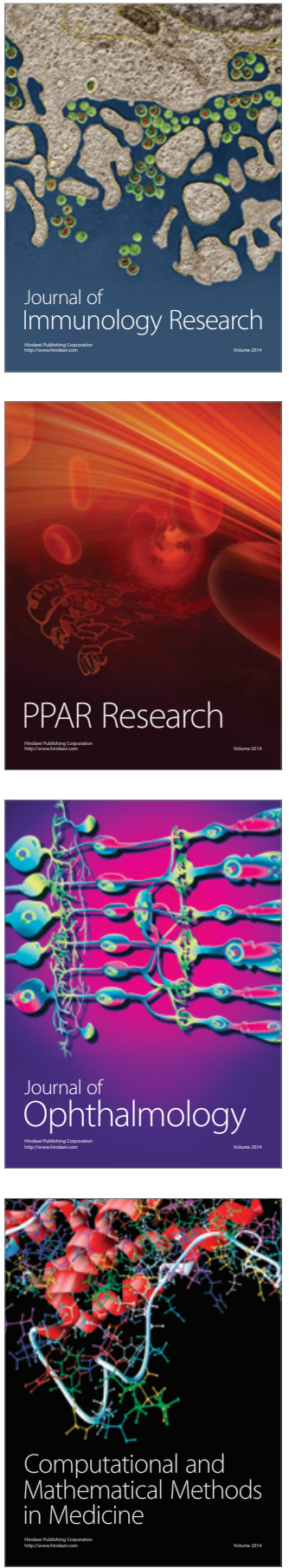

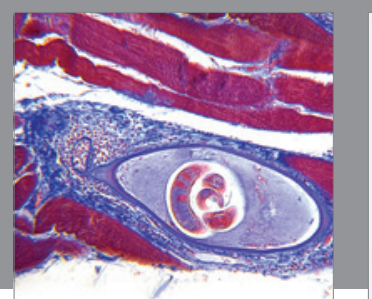

Gastroenterology Research and Practice

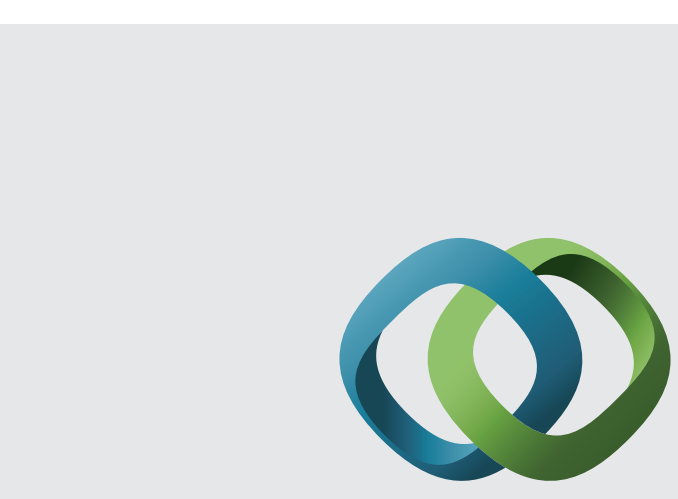

\section{Hindawi}

Submit your manuscripts at

http://www.hindawi.com
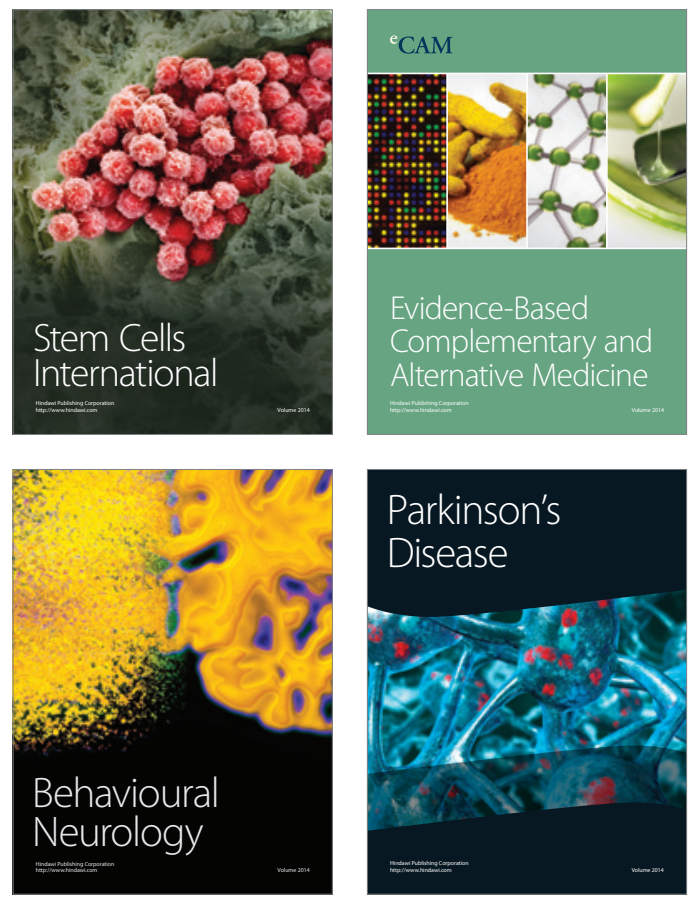
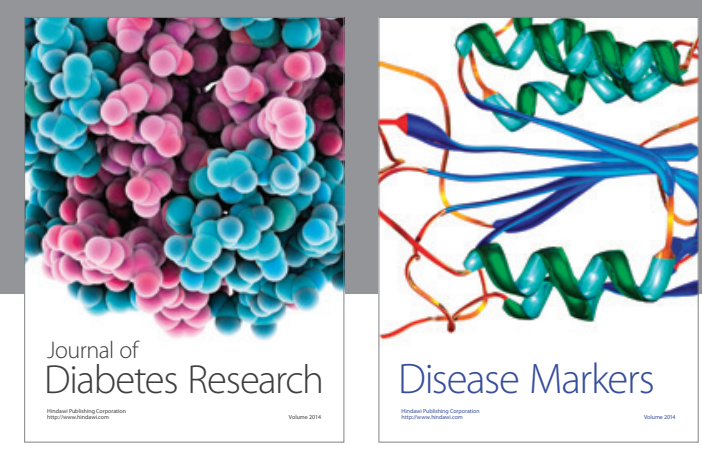

Disease Markers
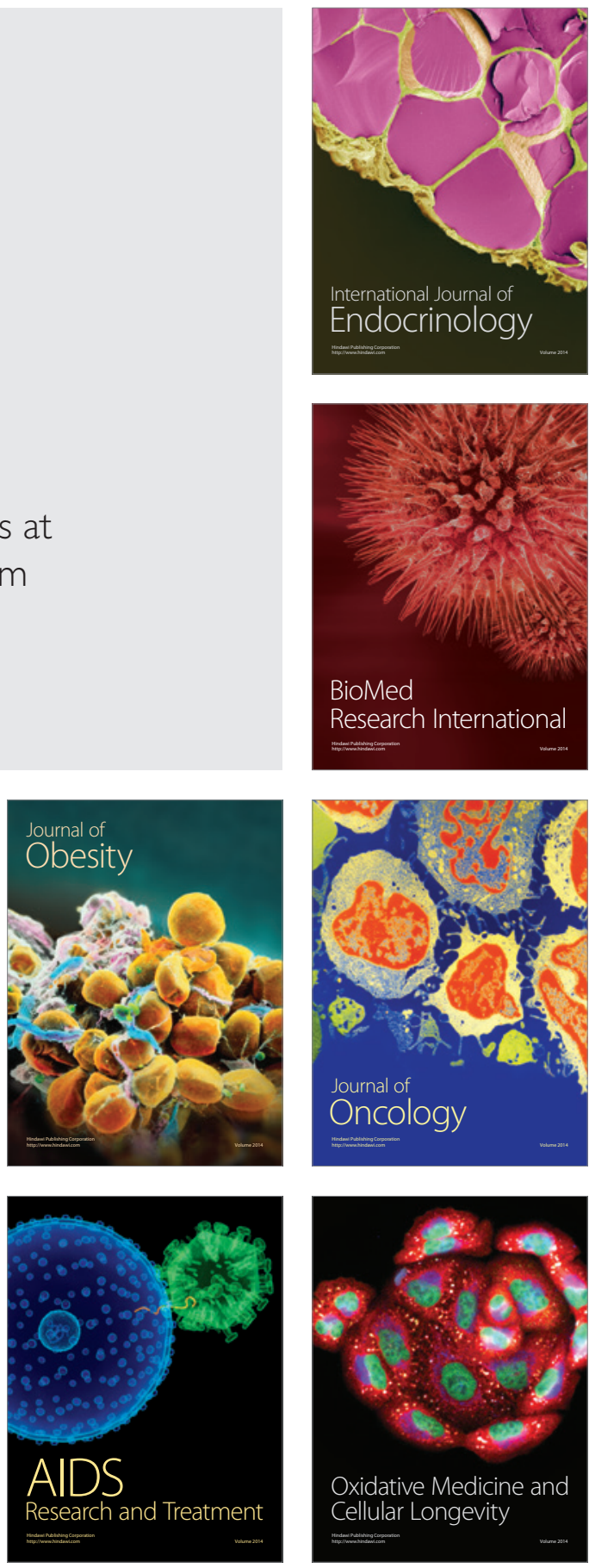